\title{
How Do City Size and Immigration Policies Affect Labor Mobility?
}

\author{
Zhuang Xia \\ Nanjing University of Posts and Telecommunications, Nanjing, China
}

\begin{abstract}
This paper uses the micro data from the National Health Commission's "China floating population dynamic monitoring survey" (CMDS) project, and uses probit and Ivprobit models to analyze the impact of policy selection on Labor mobility Decision-making under different city sizes. The results show that: (1) the larger the city size, the more conducive to labor inflow, and the externality of human capital has a positive regulatory effect; (2) the impact of city size on Labor mobility has policy screening heterogeneity, the more obvious the policy threshold, the more conducive to high-level labor inflow. Making more reasonable labor policy, reducing the threshold of labor inflow, breaking the barriers of labor inflow, balancing the gap between high skilled labor force and low skilled labor force, weakening the crowding out effect of urban scale expansion and labor policy can effectively attract talents and promote urban development.
\end{abstract}

Keywords: City size, Immigration policies, Labor mobility.

\section{Introduction}

Since the reform and opening up, in the process of urbanization in China, large-scale Labor mobility has become an important social phenomenon. According to China Statistical Yearbook 2018, there were 244 million floating population in China at the end of 2017, which is equivalent to 1 out of every 6 Chinese. Large scale and frequent Labor mobility activities reallocate China's abundant labor resources in space, improve the operation efficiency of macro-economy, provide power for economic growth, and promote the further refinement of social division of labor (Chen Rong 2019). However, Cai Fang (2016), director of the Institute of population and labor economics of the Chinese Academy of Social Sciences, said that between 2016 and 2020, China's GDP growth is expected to slow to $6.1 \%$ from $9.8 \%$ in 1995-2009, and the shrinking labor force is the main factor. Human capital is the power source of urban economic innovation and development. When China changes from "demographic dividend" to "population deficit", the economic development is hindered by the reduction of labor force, so the competition for talents between cities breaks out and intensifies. Since Wuhan put forward the slogan of "retaining millions of college students in five years" in early 2017, China's major cities have successively launched a "scramble for talents", competing to introduce preferential policies to attract general talents. City graduates from Changsha, Nanjing, Wuhan, Chengdu and Tianjin have offered graduates who are eligible for age. They can apply directly to local residents. At the same time, in order to further improve the attractiveness, most cities, on the basis of reducing the settlement requirements, also provide support in terms of minimum wage commitment, housing rental subsidies, housing purchase subsidies, living subsidies, etc., to provide a comprehensive guarantee for the introduction of talents (Liu Xuyang et al. 2019). However, the implementation effect of these preferential policies and the response of labor heterogeneity to it are not clear. Whether the talent policies issued by the city are really applicable to modern labor force and can affect Labor mobility decision-making is the problem we must explore clearly at present.

The driving force of Labor mobility comes from the pursuit of economic income, development opportunities and living environment (Wang Weitong 2019). Urban public services such as medical care, education, health and environment established on different urban scales also have significant impact on Labor mobility decision-making. Labor mobility decision-making is closely related to urban development, mainly reflected in the heterogeneity of urban scale and preferential policies. In the process of new urbanization, for cities of different sizes, there are gradient differences in terms of employment opportunities, education level, living environment, public service supply and so on (Zhang Wenwu 2018). In particular, preferential policies for talents in cities have reduced the living pressure of migrant workers to a certain extent, which has a direct impact their quality of life. Therefore, adjusting the size and pattern of cities and formulating preferential policies suitable for different characteristics of labor force is an important direction to attract labor force. What are the different impacts of different sizes of cities on Labor mobility decisions? What are the specific effects of urban policy selection on the heterogeneity of labor force? Where is the direction of urban talent policy reform? The study of these issues will help to solve the problem of Labor mobility decision-making.

\section{Theoretical Mechanism}

Migration decision-making is the most suitable decision for the purpose of migration made by the labor force according to all the information they know about the destination and their own situation. Whether the labor force is willing to move to a city or not and whether they are willing to settle down for a long time after moving in are all migration decisions. Cities that can really attract and retain labor force for a long time must be able to provide good employment opportunities for labor force, perfect social public services, and help the labor force to achieve its own development goals. On the contrary, the large-scale migration of labor force into the city is also the process of human capital accumulation, which injects 
continuous power into the city's sustainable development and further attracts more labor force.

Cities provide a spatial environment for economic activities. The expansion of urban scale will attract more enterprises to take root, which will provide a large number of jobs for labor force and promote the willingness of labor force to move in. In addition, the larger the scale of the city, the higher the average rate of per capita income can be increased by $0.031 \%$. Due to the agglomeration of human capital, the transmission of knowledge and skills is more smooth, and the acquisition cost is lower. In the process of learning from each other, workers can improve their own skills, which is ultimately reflected in the improvement of income level (Lu Ming et al., 2012; Li Rui et al., 2019). In addition, there is agglomeration economy in the city scale. The larger the city is, the higher the city's production efficiency will be, and correspondingly the higher the wages will be. An increase of $1 \%$ in urban size can bring about an average increase of $0.11 \%$ in average unit wage (Zhang Zhiqiang 2019). The driving force of Labor mobility is the pursuit of higher income level, future development and quality of life. Therefore, the expansion of urban scale brings about the increase of employment opportunities, positive externalities of human capital and the increase of wages. Higher return on human capital attracts more high skilled human capital inflow. In the process of high skilled people gathering in cities with high human capital level, it is also necessary to improve the quality of life. This has led to a large demand for low skilled labor, thus strengthening the expansion of urban scale (Xia Yiran et al. 2019). Therefore, the expansion of urban scale to a certain extent presents the characteristics of a virtuous circle.

Based on the above analysis, we propose hypothesis 1:

Hypothesis 1: the larger the size of the city, the more conducive to labor inflow, and the externality of human capital has a positive moderating effect.

The heterogeneity of labor policy exists in different urban scale, and the heterogeneity of labor policy has a significant impact on Labor mobility decision-making. In recent years, in order to "rob" and "retain" people, major cities have introduced a variety of labor policies, such as minimum wage commitment, rent subsidies, house purchase subsidies, living subsidies, etc., to a large extent, encourage the inflow of part of the labor force. However, labor policies often have certain thresholds. Liu Xuyang et al. (2019) found that the applicable objects of talent attraction policies in major cities generally have two threshold requirements: age (under 45 years old) and Education (Bachelor degree or above). There are obvious differences between subsidy policies and life inclusive policies in attracting labor force. Subsidy policies often have threshold requirements, while inclusive policies, such as preferential treatment for medical treatment and low admission threshold for children, cover almost all migrant workers. Most statistical studies have found that the threshold of labor policy keeps most of the low-level labor out of the door, while the high-level labor force is the actual object of competition in major cities. Young people with higher education level can enjoy all the benefits brought by all policies, but the labor force with lower education level can only enjoy the inclusive policies. On the surface, most policies are to reduce the living cost of labor force and encourage more labor force to move in, but indirectly squeeze out a part of the labor force with older age and lower education background. As a result, labor policy still favors young people with higher education.

Based on the above analysis, we propose hypothesis 2:

Hypothesis 2: the impact of city size on Labor mobility has heterogeneity of policy screening. The more obvious the policy threshold is, the more favorable it is for high-level labor inflow.

\section{Models and Data}

Based on the above theoretical mechanism analysis, the preferential policies for migrant workers with different urban sizes and heterogeneity are related to Labor mobility decisions. In order to verify the influence of relevant factors on the formation of Labor mobility decision-making, this paper uses probit binary selection model to analyze.

\subsection{Model Setting}

$$
\begin{aligned}
& I W_{i j}=\alpha_{0}+\alpha_{1} C_{j}+\alpha_{2} P_{i j}+\alpha_{3} C_{j} P_{i j}+\alpha_{4} X_{i j}+\varepsilon \\
& O W_{i j}=\beta_{0}+\beta_{1} C_{j}+\beta_{2} P_{i j}+\beta_{3} C_{j} P_{i j}+\beta_{4} X_{i j}+\mu
\end{aligned}
$$

Among them, $I W$ denotes the inflow and residence intention of labor force, is a binary variable, the subscript $i$ and $j$ represent the individual $i$ of the city $j, O W$ represents the reverse outflow willingness of labor force, $C_{j}$ means different cities, $P$ means the urban policy, $C_{j} P_{i j}$ is the cross term of urban scale and policy, $X_{i j}$ represents the characteristics of individual variables, $\alpha, \beta$ represents the regression coefficient, and $\varepsilon, \mu$ is random disturbance terms.

\subsection{Sample Selection and Data Processing}

The micro data used in this paper are from the "dynamic monitoring survey of floating population in China" (CMDS) project organized by the National Health Commission. Since 2009, the National Health Commission has carried out a continuous cross-sectional monitoring survey by means of questionnaires every year, covering 31 provinces, autonomous regions and cities in China where the floating population is relatively concentrated The subjects were male and female migrants who had lived in the inflow place for one month or more and were not registered in the district (county or city) and were over 15 years old. The data used in this paper is the survey data of 2017, a total of 169000 family samples covering 32 provinces, autonomous regions and municipalities directly under the central government. The basic information of family members, income and expenditure, employment situation, mobility and residence intention, health and public services, social integration and other information of migrant workers are investigated in detail. 
Referring to Zhou Yinggang et al. (2019) to study the relationship between housing prices and labor mobility, this paper takes the living willingness of labor families as the core explanatory variable. According to the migration decision of labor force, the core explanatory variable is set as the inflow and residence intention of labor force. According to the questionnaire, we find that "how long do you expect to stay here?" Questions to build. This paper uses the willingness to stay in the city for more than three years (not including three years, uncertainty, not knowing) as the main index to measure the labor force's willingness to move in. Assign 1 to those who are willing to stay in the city for more than 3 years, assign 0 to those who are willing to stay in the city for 3 years or less, and delete the samples that are not well thought out. In order to further analyze the outflow intention of migrant labor, we construct the reverse outflow intention of labor force, assign 0 to the individual labor force who intends to leave the local area, and 1 to the individual who intends to stay in the local area, and delete the sample whose answer is not good.

The core explanatory variables of this paper are city size and labor attraction policy. City size can be measured from population, land area and GDP. Because urban areas can better reflect the real economic strength and aggregation state of cities, cities are classified according to the population size of urban areas. Referring to the notice of the State Council on adjusting the standard of urban size Division issued by the State Council in 2014, based on the research needs of this paper, the urban population of less than 1 million is defined as a small city, the urban population of more than 5 million is a large city, and the urban population of 1-5 million is a medium-sized city. Li Rui et al. (2019) found that the degree of human capital externality increases with the increase of city size. The externality of human capital in large cities with more than 5 million people is $7.1 \%$ higher than that in cities with less than 5 million people. There is a positive correlation between the city size and the benefit degree of the ordinary labor force in the interaction with the urban high skilled workers, so the city size is a crucial factor in the Labor mobility decision-making.
As one of the means for the government to adjust the distribution pattern of labor force, labor policy is conducive to the optimal development of the city and the reasonable distribution of large-scale labor force. The scope and strength of preferential policies are also important factors when considering the size of the city. Therefore, this paper takes labor policy as one of the main explanatory variables. This paper classifies the explanatory variable step by step. If the city has preferential policies, it is assigned as 1 ; if there is no preferential policy, it is assigned to 0 ; in the cities with preferential policies, the policies with threshold are assigned as 1 and those without threshold are assigned as 0 ; with threshold, it means that the beneficiaries of the preferential policy are only a part of the labor force, and the rest of the labor force can not enjoy it, no threshold means that it is available to all workers. In the threshold policy, it can be divided into subsidized policies such as housing subsidies, rent subsidies, and institutional policies, such as lowering the threshold of household registration system and relaxing the Enrollment Requirements of children.

This paper refers to the existing empirical research, including some other control variables. The influencing factors of labor force's willingness to move in are summed up at the individual level. The individual characteristics of labor force, including gender, age, education level and marital status, are all control variables. Based on the research needs, the male labor force is assigned as 1 and the female labor force is assigned as 0 ; the education level below senior high school or technical secondary school (excluding senior high school or technical secondary school) is assigned as 1, senior high school or technical secondary school and college specialty is assigned as 2, and undergraduate or above is assigned as 3 . The main reasons for staying in the local area are divided into three categories: the first is personal development factors, such as income level, development space, etc. The second is family reasons, such as better education opportunities for children, marriage with local people, and the third is high quality of urban life, such as high level of medical and health care, and perfect transportation. Table 1 shows the results of descriptive statistics of variables.

Table 1: Descriptive statistical analysis of main variables

\begin{tabular}{|c|c|c|c|c|}
\hline Variable & Variable description & Observation & Mean value & Standard deviation \\
\hline Labor mobility willingness & $\begin{array}{c}\text { How long do you expect to stay in the local area? More than } 3 \\
\text { years }=1 \text {, less than } 3 \text { years }=0\end{array}$ & 105915 & 0.893896 & 0.3079721 \\
\hline Outflow intention & Do you want to stay here $?$ Yes $=1$, no $=0$ & 110098 & 0.9620338 & 0.1911153 \\
\hline City scale & $\begin{array}{l}\text { Cities with a population less than } 1 \text { million are small cities, } \\
\text { those with a population of more than } 1 \text { million and less than } 5 \\
\text { million are medium-sized cities, and those with a population of } \\
\text { more than } 5 \text { million are large cities }\end{array}$ & 78387 & 2.227627 & 0.6553106 \\
\hline Square term of city scale & & 78387 & 5.391749 & 2.839937 \\
\hline Labor policy & Divide by year & 78387 & 2010.001 & 4.027972 \\
\hline Labor policy & Divide by degree & 78387 & 3.012783 & 0.9518502 \\
\hline Public service & $\begin{array}{l}\text { Expressed by the number of hospitals in the municipal district } \\
\text { No primary school, primary school, junior high school, high }\end{array}$ & 78387 & 227.2023 & 222.3281 \\
\hline Education level & $\begin{array}{l}\text { school / technical secondary school, college, undergraduate and } \\
\text { graduate students are assigned 1-7 }\end{array}$ & 110098 & 3.545768 & 1.201823 \\
\hline Reasons for staying here & $\begin{array}{l}\text { It can be divided into personal reasons, family reasons and } \\
\text { urban reasons }\end{array}$ & 101443 & 1.88427 & 0.9004671 \\
\hline Gender & Male $=1$, Female $=0$ & 110098 & 0.5206907 & 0.499574 \\
\hline Marital status & Married $=1$, Not married $=0$ & 110098 & 0.8315864 & 0.3742349 \\
\hline $\begin{array}{l}\text { Do children have difficulties } \\
\text { in going to school }\end{array}$ & $\mathrm{Yes}=1, \mathrm{No}=0$ & 60273 & 0.3340302 & 0.4716542 \\
\hline
\end{tabular}




\section{Analysis of Empirical Results}

Firstly, without considering the endogeneity of missing variables, this paper uses probit model to analyze the relevant factors affecting Labor mobility decision. The main regression results are shown in Table 2. The models (1) - (5) in the table are probit regression. Model (1) without considering individual characteristics and other control variables, the results show that the regression coefficient of city size is 0.1424645 , which is significant at the level of $1 \%$, which indicates that given the individual characteristics and policy variables unchanged, the city size has a significant positive impact on Labor mobility decision-making, and the labor force is more willing to move to big cities. We construct the square variable of city size and find that the regression coefficient of square city size is still significantly positive. Studies have shown that the phenomenon of "wage premium" in big cities is obvious (Xi Meijun, Chen Le, etc. 2019), which can provide more employment opportunities, higher development platform, better public services and infrastructure such as education and medical treatment, and meet the quality of life pursued by contemporary young people. Although it is mentioned above that large cities may have "crowding out effect" due to traffic congestion and high consumption level, a large number of labor force still choose to flow into big cities, which shows that large cities have more advantages than small cities in choosing the target cities for Labor mobility. Furthermore, model (2) controls individual variables and urban variables, and takes labor policy as the main explanatory variable. The results show that the regression coefficient of labor policy divided by education is significant at the level of $1 \%$, while the labor policy by year is not significant, which indicates that labor force policy has obvious difference on different education background, and the higher education level of labor force is easier to obtain more preferential treatment, so they are also more willing to flow into big cities. When collecting the data of labor policy, this paper finds that both big cities, medium-sized cities and small cities have introduced institutional and subsidizing help policies to attract labor inflow. The common point is that the policies have thresholds, and the biggest threshold is education requirements. The preferential policies for labor with high and low education differ greatly, and cities prefer high technology Capable and highly educated labor force. This provides a sufficient explanation for the preference of highly skilled and highly educated labor force to big cities. At the same time, model (4) is the regression result of adding the cross item of city size and labor policy. The results show that the two variables are still significantly positive, and the regression coefficient of the cross item is negative at the significance level of $1 \%$. This may be due to the expansion of urban scale and the high level of economic development, which leads to higher education requirements of urban labor policy, which will squeeze out most ordinary education of the labor force. For example, although Shanghai, Beijing and other big cities are highly inclusive, the high cost of living and the high screening of talents will still make the low skilled and low educated labor force finally return to small cities. In model (5), this paper takes into account the control variables of public services, and the number of hospitals in municipal districts is used to represent public services. The regression coefficient of public services is significantly positive at the level of $1 \%$, which indicates that given other conditions unchanged, public services have a positive effect on Labor mobility decision. Furthermore, on the basis of given public services, model (5) shows that the regression results of urban size and labor policy (Education) are significantly positive at the level of $1 \%$, and there is no significant difference between model (1). The cross item between urban size and labor policy (Education) is still significantly negative. Therefore, it is preliminarily considered that the two main explanatory variables in this paper are robust.

Table 2: Basic regression results

\begin{tabular}{|c|c|c|c|c|c|}
\hline & model(1) & $\operatorname{model}(2)$ & model(3) & $\operatorname{model}(4)$ & $\operatorname{model}(5)$ \\
\hline \multirow{2}{*}{ City scale } & $0.1425 * * *$ & & & $0.4578 * * *$ & $0.2238 * * *$ \\
\hline & $(0.0092)$ & & & $(0.0311)$ & $(0.3897)$ \\
\hline \multirow{2}{*}{ Labor policy(degree) } & & $0.0439 * * *$ & & $0.3143 * * *$ & $0.2527 * * *$ \\
\hline & & $(0.006)$ & & $(0.0259)$ & $(0.0268)$ \\
\hline Labor policy(year) & & & $\begin{array}{l}-0.0004 \\
(0.0015)\end{array}$ & & \\
\hline \multirow{2}{*}{ City scale*Labor policy } & & & & $-0.1082 * * *$ & $-0.0709 * * *$ \\
\hline & & & & $(0.0103)$ & $(0.0111)$ \\
\hline Public service(Number of & & & & & $0.0005^{* * *}$ \\
\hline hospitals) & & & & & $(0.00005)$ \\
\hline
\end{tabular}

Notes: Significant level: $* \mathrm{p}<0.1, * * \mathrm{p}<0.05, * * * \mathrm{p}<0.01$; the figures in brackets are $\mathrm{t}$ values of robust estimation. The same below.

This paper uses micro level data to examine the impact of city size and policy selection on Labor mobility decision-making. Therefore, we include individual variables such as education level, gender, marital status, and whether children have difficulty in going to school. As shown in Table 3. In model (1), a control variable, education level, is added. The results show that the main explanatory variables in this paper are city size, labor policy (Education) and the coefficient of the two cross items are significant at the level of $1 \%$, and there is no significant difference with the regression results in Table 2.
The higher the education level, the stronger the willingness to transfer. Because people with higher education level are more likely to obtain employment opportunities, have broader development prospects, and receive more preferential policies, high skilled labor force prefers to move to big cities. The "crowding out effect" of big cities has little effect on these people, and more importantly, they squeeze out low skilled and low educated labor force. Therefore, although the big cities formulate labor policies to attract labor inflow, these policies are targeted, which virtually eliminated the low 
skilled labor force, and finally attracted more high-level and high skilled labor force. The results show that gender has a negative effect on Labor mobility decision-making, indicating that women are more willing to choose migration than men. However, the regression coefficient of gender is not significant, indicating that there is no significant difference between men and women in Labor mobility. The regression coefficient of marital status is significantly positive, indicating that the labor force in marriage is more willing to flow. This may be because people in marriage need to bear greater economic pressure, and they need to look for good employment opportunities and obtain higher income. The regression coefficient of whether the children have difficulties in going to school is significantly positive, which indicates that the labor force with difficulties in going to school is more willing to move to the big cities, because the big cities are more likely to provide good education environment for their children, which also provides a basis for people in marriage to be more willing to move to big cities, because if there are children in the marriage family, they are more likely to go to the big city to obtain More superior educational resources. Model (2) after adding the control variables, the cross items of city size, labor policy, city size and labor policy are significant. Therefore, we once again believe that the main explanatory variables in this paper are robust.

Table 3: The role of city size and policy selection on Labor mobility decision: the influence of individual characteristics

\begin{tabular}{ccc}
\hline Variable & Model (1) & Model $(2)$ \\
\hline City scale & $0.3848 * * *$ & $0.2541 * * *$ \\
& $(0.0315)$ & $(0.0456)$ \\
Labor policy(degree) & $0.2808^{* * *}$ & $0.1932 * * *$ \\
& $(0.0262)$ & $(0.0381)$ \\
City scale*Labor policy & $-0.0925 * * *$ & $-0.0618^{* * *}$ \\
& $(0.0105)$ & $(0.0153)$ \\
Education level & $0.1345^{* * *}$ & $0.1449 * * *$ \\
& $(0.0055)$ & $(0.0084)$ \\
Gender & & -0.0131 \\
& & $(0.0180)$ \\
Marital status & & $0.5157 * * *$ \\
Do children have difficulties in & & $(0.0237)$ \\
going to school & $0.3058^{* * *}$ \\
Notes: Significant level: ${ }^{*} \mathrm{p}<0.1, * * \mathrm{p}<0.05, * * * \mathrm{p}<0.01 ;$ the figures in \\
brackets are t values of robust estimation. The same below.
\end{tabular}

\section{Conclusion and Suggestion}

This paper uses the micro data of China's floating population dynamic monitoring survey (CMDS) project and probit regression analysis to examine the impact of city size and policy selection on Labor mobility decision-making. It is found that the heterogeneity of urban scale is an important factor affecting the decision-making of Labor mobility. The willingness of labor force to flow to big cities is stronger than that of small cities. Public services such as education, medical resources and infrastructure in big cities are more perfect, which is a very important factor at the city level to attract labor force. Especially for the high skilled and highly educated workers who pursue high-quality life, they pay more attention to the long-term life plan. For the labor force with families and children, big cities can provide more perfect life security.

This paper also analyzes the impact of labor policy on Labor mobility decision. We find that the threshold of labor policy is particularly significant in terms of educational background, and the gap of labor subsidy for different education background is obvious. Although the labor policy is ostensibly to attract and retain more labor force, the significant threshold of the policy indirectly excludes the low educated and low skilled labor force. Labor policy is a tool to select high-quality labor force, providing and reserving talent for big cities. Generally speaking, the threshold for low skilled and low educated workers to enter big cities is still high.

\section{References}

[1] Cai Fang. (2018). Registered residence system reform is the key to breaking the barriers of rural mobility. Rural Work Communication, (20), 25.

[2] Gu Yingwen, Shang Yue. (2020). The impact of living conditions on the health of floating population: An Empirical Study Based on the dynamic monitoring data of floating population in Hubei Province in 2017. Statistics and Management, 35 (03), 89-95.

[3] Ji Shao, Li Xiaoliang. (2019). Rural labor mobility and employment system, policy evolution and innovation since the reform and opening up. Economic and Management Research, 40 (01), 64-74.

[4] Liang Qi, Chen Qiangyuan, Wang Ruyu. (2013). China registered residence reform, labor mobility and city hierarchy system optimization. Chinese Social Sciences, (12), 36-59+205.

[5] Ma Jing, Shi Qiong, Zhao Ruyu. (2019). Influencing factors and policies of urban labor employment: a case study of Binjiang District, Hangzhou City. China Economic and Trade Guide (Middle), (04), 125-127.

[6] Wang Lili, Qiao Xue. (2020). Migration cost, city size and productivity in China. Economics (Quarterly), 19 (01), 165-188.

[7] Zhang Wenwu, Ou Xi, Xu Jiajie. (2018). Urban scale, social security and the willingness to citizenize agricultural transfer population. Agricultural Economic Issues, (09), 128-140.

[8] Zhang Wenwu, Zhang Weifu. (2020). What makes cities abler to retain people? World Economic Journal, (03), 31-45.

[9] Zhou Yinggang, Meng Lina, Lin Xueping. (2020). Urban inclusiveness and the entrepreneurial choice of labor force: Based on the micro perspective of floating population. Finance and Trade Economy, 41(01), 129-144.

[10] Zhu Zhisheng. (2016). The influence of city size on employment welfare effect. Urban Issues, (01), 71-77. 